\title{
əThe Influence of the Wind Field and Stratification on the Nocturnal Surface Air Temperature over Modest Topography
}

\author{
L. Mahrt, ${ }^{a}$ H. J. S Fernando, ${ }^{b}$ And O. AceVedo ${ }^{c}$ \\ ${ }^{\mathrm{a}}$ Northwest Research Associates, Corvallis, Oregon \\ ${ }^{\mathrm{b}}$ University of Notre Dame, Notre Dame, Indiana \\ ${ }^{\mathrm{c}}$ Universidade Federal de Santa Maria, Santa Maria, Rio Grande do Sul, Brazil
}

(Manuscript received 2 February 2021, in final form 15 July 2021)

\begin{abstract}
Our study examines the horizontal variation of the nocturnal surface air temperature by analyzing measurements from four contrasting networks of stations with generally modest topography. The horizontal extent of the networks ranges from 1 to $23 \mathrm{~km}$. For each network, we investigate the general relationship of the horizontal variation of temperature to the wind speed, wind direction, near-surface stratification, and turbulence. As an example, the horizontal variation of temperature generally increases with increasing stratification and decreases with increasing wind speed. However, quantitative details vary significantly between the networks. Needed changes of the observational strategy are discussed.

SIGNIFICANCE STATEMENT: We analyze nocturnal measurements from four different networks of surface stations over different types of terrain. We concentrate on the spatial variation of the surface air temperature that controls frost damage, fog formation, dispersion of particulates, and the effects of terrain changes on climate. For each network, our study examines the general relationship of the horizontal variation of temperature to the wind speed, wind direction, vertical variation of temperature, and turbulence. We identify important inadequacies of the observations and the need for future more appropriate network design including instrumental needs and choice of sites.
\end{abstract}

KEYWORDS: Land surface; Boundary layer; Drainage flow; Eddies; Freeze events; Katabatic winds; Microscale processes/variability; Surface layer; Surface temperature; Surface observations

\section{Introduction}

Horizontal variations of surface air temperature are often large during nocturnal conditions with low wind speeds and relatively clear skies (e.g., Medeiros and Fitzjarrald 2015). Such variations are driven by a variety of factors including surface heterogeneity, topography, and transient motions. Abraham and Monahan (2020) found that transitions between weakly stable and very stable conditions also generate significant horizontal variability of temperature when these transitions are local and not spatially simultaneous. Errors in prediction of local horizontal variations of temperature at night can have secondary consequences. For example, Smith et al. (2020) identified nocturnal examples where numerical models produce valleys that are too warm and hills that are too cold, leading to underprediction of fog in valleys and overprediction of fog on hilltops.

Topography often organizes temperature variations through the formation of cold pools that form in lower lying areas. Although, the term "cold pool" includes a wide variety of phenomena, cold pools are most clearly defined in nearly enclosed basins (Zhong et al. 2001; Lu and Zhong 2014), sink holes, and craters (Whiteman et al. 2004; Lehner et al. 2017).

¿ Denotes content that is immediately available upon publication as open access.

Corresponding author: L. Mahrt, mahrt@nwra.com
Basins that have relatively small outflows allow formation of well-defined strong cold pools. De Wekker and Whiteman (2006) demonstrated that nocturnal cooling commenced more rapidly in basins and valleys relative to cooling over flat terrain. Cold pools are eliminated mainly by increasing large-scale flow or cold-air advection above the cold pool (Zhong et al. 2003).

With most topographical geometries, cold pools are more complex. The term cold pool is commonly applied to cold air in valleys of any shape and is applied to even very small shallow valleys that are embedded within larger cold pools. Such cold pools are able to tolerate some loss of cold air due to downvalley flow. Katabatic flows down the side slopes of a valley often extend over the top of the valley cold pool, or the interaction of the katabatic flow and valley flow is more complex (Fernando et al. 2015). The cold air can begin in small upland tributary gullies that flow into a valley. Down-valley flows converge into larger valleys, and so on. Eventually the cold air may extend over a large plane (Banta et al. 1995) or flow over the sea. Flow to the sea is particularly complex with coastal urban areas (Leo et al. 2015).

Most valleys are characterized by some three-dimensionality. Bending of valleys or a down-valley increase of sheltering by side slopes (Vosper et al. 2013) often promote a decrease of temperature in the down-valley direction. Valley constrictions also lead to buildup of cold air and colder surface temperatures (Lundquist et al. 2008; Sheridan et al. 2013). Up-valley flow prevents cold air from descending farther down the valley and consequently promotes buildup of cold air (LeMone et al. 2003). 
Stiperski and Rotach (2016) found that the spatial variation of the slope magnitude sometimes leads to acceleration or deceleration of the down-slope flow. They show that sufficient variation of the slope leads to microscale flow separation when the stratification is weak and wind speeds are sufficiently high. Stiperski and Rotach (2016) revealed that quantification can be sensitive to the data processing choices and coordinate rotation method even over small slopes.

A variety of small-scale features collectively induce complex, but important, horizontal variations of temperature. Spatial temperature variations are caused by lee recirculation, smaller-scale lee turbulence, and ridge gap flows (Menke et al. 2019; Vassallo et al. 2021). Moderate flow might intermittently reduce or eliminate shallow cold pools (Mahrt and Heald 2015). Cold pools are often eroded by downward transport of turbulence associated with overlying low-level jets and transient wavelike motions (Jemmett-Smith et al. 2019), which lead to a degree of unpredictability. Wavelike motions and lee vortices sometimes lead to sloshing of the cold pool that temporarily ascends the slope leading to a decrease of temperature on the slope (Lehner et al. 2015; Connolly et al. 2021). Despite such complications, Sheridan et al. (2013) showed that the difference of air temperature between the valley bottom and higher up the slope systematically increased with increasing bulk stratification and decreasing wind speed of the undisturbed approach flow, as defined in their section 3 .

Less is known about the observed impact of surface heterogeneity on nocturnal variations of air temperature beyond generation of greater mixing and higher air temperatures above patches of greater roughness. Weak surface heterogeneity is sometimes important in the stable nocturnal boundary layer where eddies are small but not in the convective boundary layer where the eddies are larger and more energetic. Bou-Zeid et al. (2020) provides an extensive interpretive survey of the impact of surface heterogeneity on the generation of horizontal gradients of temperature and other quantities. They survey different approaches and concepts applied to the impact of surface heterogeneity. With well-defined changes of surface characteristics, internal boundary layers often form that generally lead to organized horizontal variations of temperature. Most surfaces are more complex than a single sharp discontinuity of surface characteristics yet still produce local circulations (Fernando 2010). Bodine et al. (2009) and Guerra et al. (2018) showed that local higher vegetation and associated vegetation sheltering significantly modifies the temperature patterns.

From a more practical point of view, statistical models are constructed without specific identification of flow regime. Sheridan et al. (2018), and citations therein, found that downscaling temperature from larger-scale observations to smaller scales, using information on model resolved vertical structure, approximated the temperature distribution in a valley cold-pool system. Lundquist et al. (2008) applied empirical orthogonal functions to networks of distributed temperature sensors in three different regions to identify geographic locations prone to cold-air pooling. They developed an algorithm using digital terrain data to successfully predict these locations. In addition to slope, a scale-dependent curvature significantly influences the formation of cold pools (Lundquist et al. 2008).
Ultimately, improved understanding of the physics is required that has been recently advanced through studies in a shallow valley using a network of flux stations, a tower, and fast-response temperature measurements with fine-scale horizontal resolution provided by fiber-optic distributed temperature sensing (Pfister et al. 2021a). Based on such data, Pfister et al. (2019) found that the usual classification schemes for the nocturnal boundary layer is oversimplified and that classification schemes should include downwelling longwave radiation instead of the net radiation. Cold air at the bottom of the slope may be partly due to nonlocal advection from distant sources (Pfister et al. 2017). Pfister et al. (2021a) also demonstrated that common temperature fronts on the submesoscale (thermal submesofronts) play an important role in organizing the temperature on the slopes that form from warm air originating from topographically induced mixing and cold air from cold-air advection and local cold-air pooling. Because the thermal submesofronts propagate slowly, they are not easily captured by the network of stations. Furthermore, the thermal submesofronts occur under a variety conditions and boundary layer classifications, excluding the highest wind cases (Pfister et al. 2021b). These nonstationary phenomena contribute to the difficulty of predicting the spatial pattern of air temperature from elevation and flow regime based on observations from fixed points.

Recognizing these complexities, we forego predicting the complex temperature patterns and pursue examination of a simple overall measure of the magnitude of spatial distribution of temperature over four networks, each with a different type of topography. Here, the temperature variability is posed as a simple standard deviation between stations, and in some cases, based on differences between selected stations to examine specific parts of the network. Within-night and between-night spatial variation of surface air temperature will be studied as a function of wind speed, stratification or stability, and turbulence. Precise conclusions are partially hampered by network-dependent instrumentation, processing methods, and deployment strategies (such as observational heights, station spacing and network size).

After introducing the networks (section 2) and the analysis strategy (section 3), we briefly note the dependence of temperature on surface elevation for the different networks (section 4). Section 5 explores the dependence of the spatial variation of temperature on the stratification and wind speed (or stability parameters). Section 6 contrasts the dependence of horizontal temperature variation on wind speed between the different networks. Section 7 focuses on temperature variations for smaller-scale (subnetwork) topographical features such as gullies and small-scale three-dimensional topography.

\section{Measurements}

Comparing analyses between different networks is an important part of this study. We now summarize the basic characteristics of the four networks. The Shallow Cold Pool Experiment (SCP) is the primary dataset because it includes the most extensive instrumentation, and the network is located over relatively simple topography with only nominal heterogeneity of 


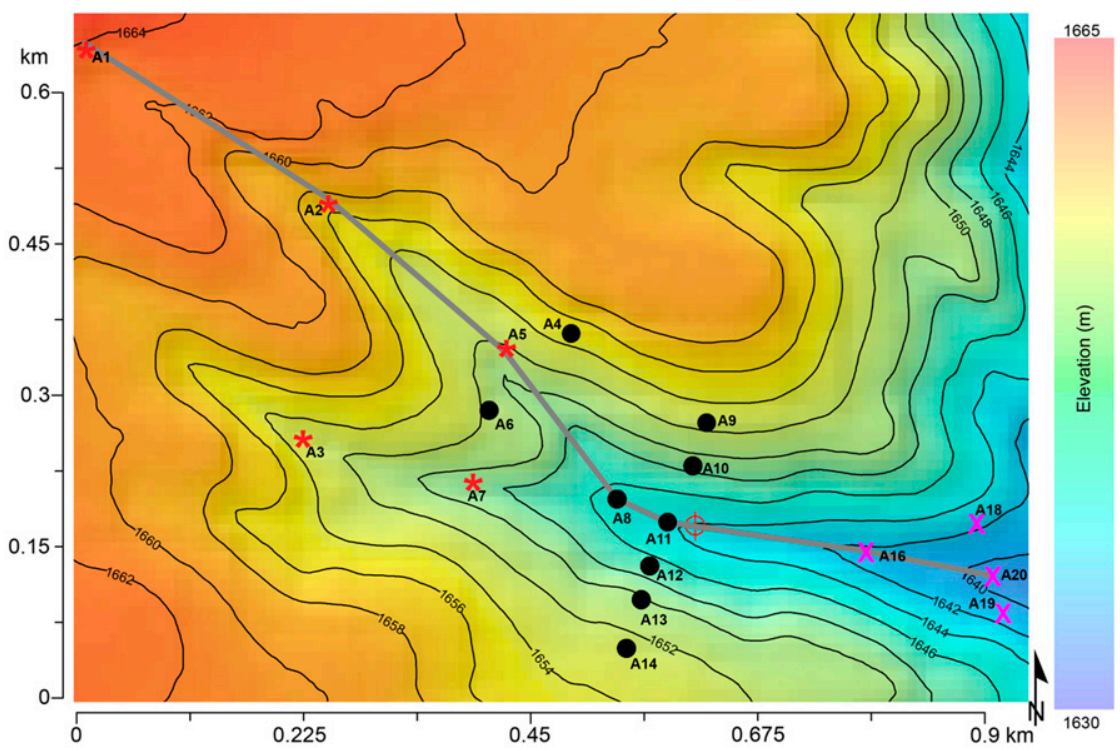

FIG. 1. The spatial distribution of 1-m temperature observations. For future use, the stations are partitioned into those on the cross-valley transect (A9-A14) and nearby (A4, A6, and A8) (black circles), the western tributary gullies (red asterisks: A1, A2, A3, A5, and A7), and the down-valley stations (magenta Xs: A16, A18, A19, and A20). The red open circle with cross locates the main tower. The segmented gray line identifies stations on the valley floor, plotted in Fig. 10a, below.

the vegetation. SCP was conducted over semiarid grasslands in northeastern Colorado, from 1 October to 1 December 2012 (https://www.eol.ucar.edu/field_projects/scp). The main valley is relatively small, roughly $12 \mathrm{~m}$ deep and $270 \mathrm{~m}$ across (Fig. 1). The network is about $800 \mathrm{~m}$ in the down-valley direction. The width of the valley floor averages about $5 \mathrm{~m}$ with an average down-valley slope of about $2 \%$, increasing to about $3 \%$ at the upper end of the valley. The side slopes of the valley are on the order of $10 \%$ or less. We analyze the $1-\mathrm{m}$ sonic anemometer (CSAT3 from Campbell Scientific, Inc.) observations from 20 stations and also consult observations from the main $20-\mathrm{m}$ tower, which includes profiles of temperature, wind, and the fluxes. We estimate the near-surface stratification from the NCAR hygrothermometers deployed at the 0.5- and 2-m levels at 19 of the stations. Near-surface stratification for the other networks is either not available or had issues.

The Pedras Altas campaign was conducted in August and September 2013 at Pedras Altas in southern Brazil (Guerra et al. 2018). The Pedras Altas site is located $400 \mathrm{~m}$ above sea level in a region known as Pampa Gaucho. The region is characterized by small hills with grass, shrubs, and small trees. The network is embedded within a single slope with a typical slope value of $7.5 \%$ (Fig. 2). The network elevation change is about $35 \mathrm{~m}$ while the elevation change for the entire slope is about $70 \mathrm{~m}$. The downslope distance of the network is about $500 \mathrm{~m}$ with a cross-slope width of about $1 \mathrm{~km}$. The slope on the opposite side of the valley is significantly shorter with a total elevation change of about $30 \mathrm{~m}$. The network includes six stations with 034B Met-One, Inc., cup anemometers and three stations with Vaisala, Inc., WXT520 All-in-One instruments at $2.5 \mathrm{~m}$. We eliminated station 2 because of frequent missing data. Station 6 is the highest station and has the highest winds speeds. Some of the highest wind speeds were considered to be unlikely, and this station was also eliminated. Station 1 was located in a low lying area with some surrounding bushes and characterized by the lowest wind speeds. This station is retained.

The Perdigão network in Portugal (Fernando et al. 2017, 2019) covers a deep valley defined by two relatively steep side slopes with variable surface vegetation. Side slopes average about $20 \%$. The network width is a little less than $1.6 \mathrm{~km}$ in the cross-valley direction, and the valley depth is about $250 \mathrm{~m}$ (Fig. 2). The network consists of 19 stations with CSAT sonic anemometers at $10 \mathrm{~m}$ that were also used for temperature. The higher observational level is partly motivated by the surface heterogeneity and larger roughness elements. The substantial vegetation contributes to between station variation. Because the Perdigão field program is dominated by ridgetop measurements, we average measurements from the five exposed ridgetop stations to form a single ridgetop value. We combine the ridgetop average with the two valley stations and five stations on a side slope transect to form a subset of eight stations. The temperature erratically increases up the slope transect presumably due to local surface heterogeneity of the vegetation. The wind directions on the ridge are remarkably confined to two wind-direction sectors, $120^{\circ}-180^{\circ}$ and $320^{\circ}-20^{\circ}$. Because the valley axis is roughly aligned from southwest to northeast, both groups include significant cross-valley flow above the valley floor. A more general description of the project can be found online (https://www.eol.ucar.edu/field_projects/Perdigão.)

The topography of the "FOG-82" network in New York (Acevedo and Fitzjarrald 2003) is more complex, with multiple 
Perdigão

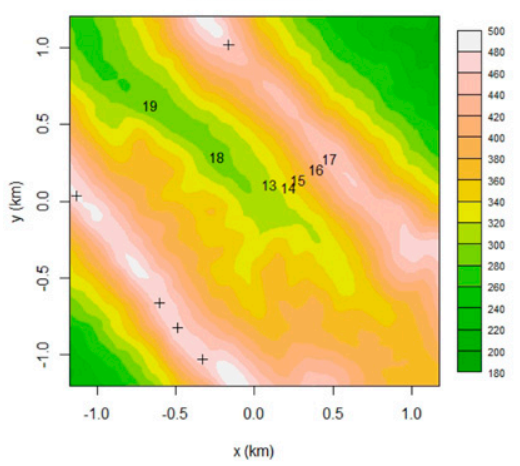

Pedras Altas

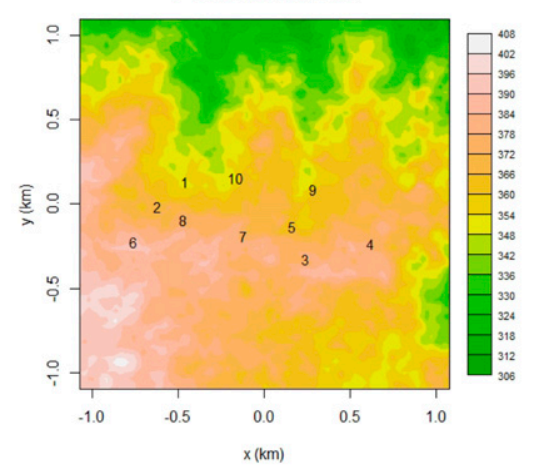

FOG-82

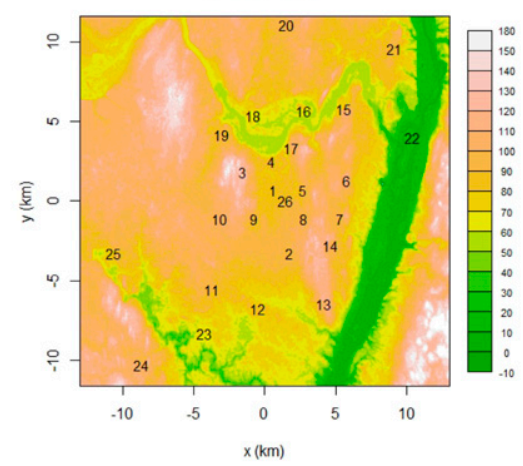

FIG. 2. Topographic maps and station locations for the Perdigão, Pedras Altas, and FOG-82 networks. The plus signs for the Perdigão network identify the five ridgetop stations that are averaged to obtain one ridgetop value.

shallow irregular valleys and two larger valleys and widespread surface heterogeneity of the vegetation. The network of 26 stations is confined to an area of about $30 \mathrm{~km} \times 30 \mathrm{~km}$, which is the largest of the four networks (Fig. 2). Terrain elevation ranges from 10 to $140 \mathrm{~m}$. Small-scale low-amplitude terrain features can dominate the between station temperature differences. Such features are hard to identify in Fig. 2 because of the large scale of the network. The network of 26 Portable Automated Mesonet (PAM) stations operated from 7 September 1982 to 7 November 1982. Temperature was measured by an aspirated thermistor, wind speed by a cup anemometer and wind direction by a wind vane. All sensors were located at $2 \mathrm{~m}$ above the ground, except the wind sensors were located at $4 \mathrm{~m}$. Several stations are within a suburban setting. Of the 26 stations in FOG-82, stations 7 , 9 , and 22 were eliminated by quality control and missing data considerations. Turbulent fluctuations were not measured.

Table 1 provides some basic characteristics for each network. Determination of the network width is somewhat ambiguous, particularly with networks that have irregular shapes and variable station spacing. Here, the network width is estimated in terms of the approximate length of the major (longest) axis of the network. For FOG-82, the network includes a variety of valleys of different sizes and depths so that no value for the valley depth is given in Table 1. For the Pedras Altas site, the width and depth are for a single slope, whereas the network occupies about one-half of the slope.

The station spacing must be suitably small that correlations between adjacent stations are significant, even for low wind speeds, to avoid omission of important small-scale variability (Staebler and Fitzjarrald 2004). In general, the correlation between adjacent stations was significant in the four networks although this correlation decreased with decreasing wind speed.

A local potential temperature at each station is defined with respect to the lowest station in the network by using the dry adiabatic lapse rate between this station $Z_{\text {base }}$ and the elevation of the other surface stations $Z$ such that the potential temperature at a given station is

$$
\theta \equiv T+0.01\left(\mathrm{~km}^{-1}\right) \times\left(Z-Z_{\text {base }}\right)
$$

We define the nocturnal period from 2100 local standard time (LST) to $0600 \mathrm{LST}$ to exclude the complex transition periods (Angevine et al. 2020). We have examined the sensitivity to the choice of these selection times. The results were at least qualitatively similar and the conservative fixed times independent of season are used here to make the results more easily reproducible by others. We have previously used time limits that varied daily based on the local sunset and sunrise times. Results were qualitatively the same except the analysis based on the fixed times loses some data during the longer nocturnal periods.

\section{Basic analysis of the surface air temperature, wind, and turbulence}

\section{a. Averaging}

The Perdigão and SCP networks provide fast response turbulence measurements at all of the network stations. For these sites, the flow is partitioned as

$$
\phi=\phi^{\prime}+\bar{\phi}
$$

where the overbar designates a time average over a window of width of $1 \mathrm{~min}$, unless otherwise noted; $\phi$ represents $\theta$ or one of the velocity components. Based on the dependence of the fluxes on the averaging time, the 1-min averaging removes most of the turbulent fluctuations, except possibly for the windiest near-neutral conditions. For more stable records, the vertical velocity perturbations will include nonturbulent

TABLE 1. Network name, project duration (weeks), network width $(\mathrm{km})$, and valley depth $(\mathrm{m})$.

\begin{tabular}{lcccc}
\hline \hline \multicolumn{1}{c}{ Site } & $\begin{array}{c}\text { Duration } \\
\text { (weeks) }\end{array}$ & $\begin{array}{c}\text { No. of } \\
\text { stations }\end{array}$ & $\begin{array}{c}\text { Width } \\
(\mathrm{km})\end{array}$ & $\begin{array}{c}\text { Depth } \\
(\mathrm{m})\end{array}$ \\
\hline SCP & 8 & 20 & 0.8 & 12 \\
Pedras Altas & 8 & 10 & 1 & 70 \\
Perdigão & 13 & 19 & 1.6 & 250 \\
FOG-82 & 9 & 26 & 23 & \\
\hline
\end{tabular}


fluctuations and the horizontal velocity fluctuations may be dominated by nonturbulent motions. In fact, the turbulent and nonturbulent fluctuations sometimes overlap in time scale (Mahrt and Thomas 2016). The heat flux is computed as $\overline{w^{\prime} \theta^{\prime}}$, where $w^{\prime}$ is the perturbation vertical velocity.

We represent horizontal averages of $\bar{\phi}$ across the network flow as $\langle\phi\rangle$. Averages of $\bar{\phi}$ over the entire field program at fixed points are written as $[\phi]$. Averages of the spatial mean over the entire field program are written as $[\langle\phi\rangle]$. Some of the analyses will be based on bin-averaged quantities in terms of intervals of a forcing variable such as wind speed or stratification. Generally, the bins for low and intermediate wind speeds include a large number of points so that the standard error is very small and often not visible on the plots. However, the uncertainty is probably substantially underestimated by the standard error, because the samples are not independent given the significant nonstationarity in stable conditions (Mahrt and Thomas 2016).

The wind speed is determined as

$$
U \equiv \sqrt{\bar{u}^{2}+\bar{v}^{2}} .
$$

The network averaged wind speed is computed from the network-averaged wind components as

$$
\langle U\rangle \equiv \sqrt{\langle u\rangle^{2}+\langle v\rangle^{2}}
$$

and thus represents the speed of the wind vector averaged over the network.

\section{b. Turbulent mixing}

We expect that significant vertical mixing by the turbulence reduces the horizontal variations because sufficient vertical mixing couples the local surface wind and temperature to the flow over a deeper layer. To reduce the impact of nonturbulent motions on the estimated vertical velocity fluctuations, we define (Mahrt et al. 2013)

$$
R \sigma_{w} \equiv R_{w \theta} \sigma_{w^{\prime}}=-\frac{\overline{w^{\prime} \theta^{\prime}}}{\sigma_{\theta^{\prime}}},
$$

where $R \sigma_{w}$ is the reduced vertical velocity scale, $R_{w \theta}$ is the correlation between the potential temperature fluctuations and vertical velocity fluctuations, and $\sigma_{w^{\prime}}$ and $\sigma_{\theta^{\prime}}$ are the standard deviations of the time fluctuations of the vertical velocity and potential temperature, respectively. This velocity scale more accurately represents the turbulence responsible for the mixing and filters out vertical velocity fluctuations that do not contribute significantly to the heat flux, such as gravity waves. Relative to $\sigma_{w^{\prime}}, R \sigma_{w}$ responds more closely to the wind profile, including low-level wind maxima in drainage flows and vanishing shear layers.

\section{c. Stability}

The stratification is defined in terms of the difference of potential temperature between two levels, $\delta_{z} \theta$, which is then averaged over the network to obtain $\left\langle\delta_{z} \theta\right\rangle$. Quality measurements of $\delta_{z} \theta$ are available for all of the stations in the SCP network.
One of the difficulties of identifying the impact of stability is that the bulk Richardson number can approach extremely large values when the wind speed approaches very small values. Alternatively, the surface-layer Froude number is defined as

$$
\mathrm{Fr} \equiv \sqrt{\frac{\langle U\rangle^{2} \Theta}{g z\left\langle\delta_{z} \theta\right\rangle}} ;
$$

Fr is the inverse square root of the surface bulk Richardson number that is well behaved for low-wind speeds, the emphasis of our study. The ratio $z / L$ is also a useful measure of the stability if the fluxes do not vary too much with height between the surface and the observational level; $z / L$ is computed from spatially averaged fluxes for the SCP and Perdigão networks and is used in section 5 .

Scaling variables to form nondimensional axes often create shared variables and self-correlation [see Grachev et al. (2007) and citations therein]. In addition, the choice of the scaling quantities for submeso variations between turbulence length scales and the network size is not completely clear. Thus, creating dimensionally consistent axes is not a priority for this study. For the SCP network, $z / L, \operatorname{Fr},\langle U\rangle$, and $\left\langle\delta_{z} \theta\right\rangle$ are all well correlated partly because greater wind speed leads to more turbulent mixing and reduction of the stratification, although Lapworth and Osborne (2020) found that even very weak topography can alter the exact relationship between the stratification and wind speed.

\section{Dependence of surface air temperature on surface elevation}

Nocturnal surface air temperatures are generally found to be higher at higher elevations and lower at lower elevations although this dependence can be complex (Lundquist et al. 2008). Here, we contrast this dependence on surface elevation between the four networks. The surface elevation $Z_{\text {sfc }}$ can be an unreliable predictor of the surface potential temperature, particularly for the FOG-82 network (Fig. 3). The relationship is useful for the Perdigão network (Fig. 3b) where the network spans a deep and organized valley. Here, the potential temperature tends to increase with elevation up to about $60 \mathrm{~m}$ above the valley floor and then becomes independent of elevation up to the highest elevations of about $200 \mathrm{~m}$ above the valley floor (Fig. 3b), at least within the substantial scatter. This suggests a deep cold pool of about 60-m depth. Despite the well-organized valley-ridge system in Perdigão, the scatter is still significant probably because of different land uses and the potential influence of lee recirculation and gap flows (Menke et al. 2019; Vassallo et al. 2021).

For the Pedras Altas network (Fig. 3c), the averaged temperature depends systematically on elevation. This network is confined to a single slope. Some scatter remains partly because of the influence of smaller-scale variations of the terrain, on the scale of tens of meters, and the influence of surface heterogeneity of the vegetation.

The dependence of temperature on $Z_{\mathrm{sfc}}$ is poor at the SCP site (Fig. 3a) despite what appears to be a relatively simple 

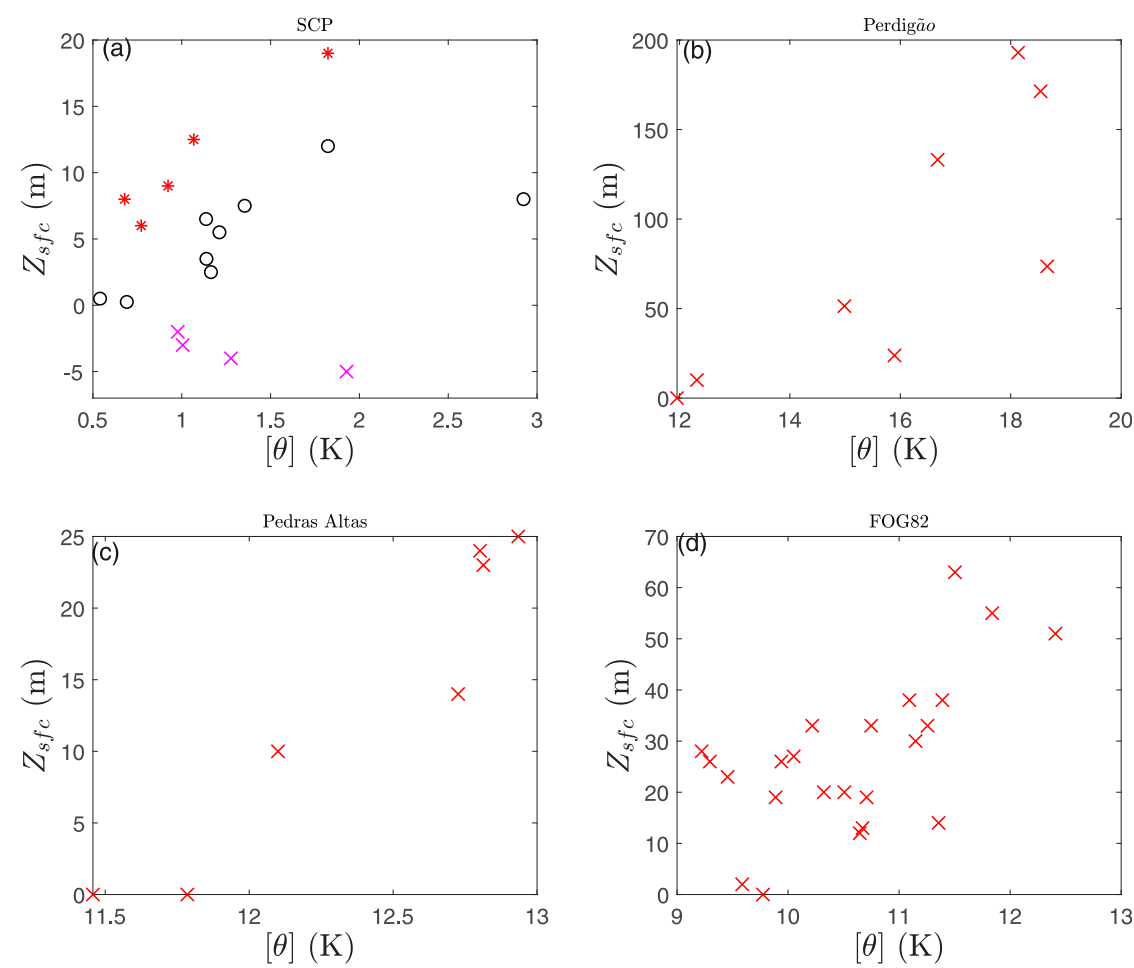

FIG. 3. The dependence of the mean potential temperature on the station elevation at (a) SCP, (b) Perdigão, (c) Pedras Altas, and (d) FOG-82. The $Z_{\text {sfc }}$ is relative to the minimum elevation among the stations in the network except for the SCP network, for which $Z_{\mathrm{sfc}}$ is relative to the elevation of the tower base. For SCP, stations are partitioned into those on the cross-valley transect (A9-A14) and nearby (A4, A6, and A8) (black open circles), the western part of the network (red asterisks: A1, A2, A3, A5, and A7); and the down-valley stations (magenta Xs: A16, A18, A19, and A20). See Fig. 1. There are no restrictions on wind speed or stratification.

valley system. If we partition the stations into subareas, the relationship between $[\theta]$ and $Z_{\text {sfc }}$ improves. For stations on the cross-valley transect and nearby stations (black asterisks), the temperature increases systematically with elevation except for station A9, which is influenced by lee warming events (Mahrt 2017b). The temperature also increases systematically with elevation for the higher western part of the network (red asterisks), which includes two tributary gullies. For the eastern lower part of the network, the temperature actually increases with decreasing elevation where the valley side slopes become lower and gentler with less sheltering. If we remove the stations on the down-valley transect (magenta), the relationship between temperature and elevation for the network improves significantly.

The relationship of $[\theta]$ to $Z_{\text {sfc }}$ is also characterized by considerable scatter at the large complex FOG-82 site (Fig. 3d), which includes multiple shallow irregular valleys and surface heterogeneity. Acevedo and Fitzjarrald (2001, 2003 ) found that the dependence of $[\theta]$ on station elevation in this network is improved by using the deviation of the station elevation from a subnetwork average of area $3 \mathrm{~km} \times 3 \mathrm{~km}$, instead of the average surface elevation over the entire network of about $23-\mathrm{km}$ width. The deviation of the elevation from the $3 \mathrm{~km} \times 3 \mathrm{~km}$ average provides a local estimate of the Laplacian of the terrain and thus a local estimate of the terrain curvature. Medeiros and Fitzjarrald (2015) found that a turbulence intermittency index was greatest with small terrain curvature or positive curvature (concave). The intermittency index was found to be small with negative (convex) curvature of the terrain. From a more general point of view, using high-resolution digitized elevation data to include terrain curvature improves prediction of the horizontal variation of temperature (Lundquist et al. 2008).

\section{Quantitative measure of spatial variation of surface air temperature and dependence of wind speed and stability}

\section{a. Temperature spatial variation}

The analysis strategy is to relate the horizontal variations of the temperature to the general forcing, which includes the geometry of the topography, wind speed and direction, stratification, and turbulence. The horizontal variation of the wind and temperature can be most simply formulated as the standard deviation of the temperature and wind components across the network to compute $\sigma_{u}, \sigma_{v}$, and $\sigma_{\theta}$. For example, 


$$
\sigma_{\theta} \equiv \sqrt{\frac{1}{K} \sum_{1}^{K}\left[\theta^{*}(k)\right]^{2}},
$$

where

$$
\theta^{*}(k) \equiv \bar{\theta}(k)-\langle\theta\rangle,
$$

$k$ is the station number, $K$ is the number of stations, and $\langle\theta\rangle$ is the average of $\bar{\theta}$ over all of the stations. This simple approach is analogous to that constructed to evaluate the representativeness of wind measurements at fixed points applied by van den Bossche and De Wekker (2018). We will also examine the difference of $\theta$ between strategically selected stations such as one station on the valley floor and one on the hill or ridgetop (section 7).

Artificially decreasing the horizontal resolution of the network by removing stations increases $\left[\sigma_{\theta}\right]$ because the average horizontal separation between stations increases. Increasing the averaging time from 1 to $5 \mathrm{~min}$ at the SCP site, for example, decreases $\left[\sigma_{\theta}\right]$ by about $25 \%$ due to filtering out the horizontal variations on time scales between 1 and $5 \mathrm{~min}$. The $\left[\sigma_{\theta}\right]$ is expected to decrease with height above the ground in that the influence of the surface topography and surface heterogeneity is expected to decrease with height. However, the three observational heights with horizontal coverage-0.5, 1.0, and $2.0 \mathrm{~m}$ above ground at the SCP site-are too close together to detect the height dependence of $\left[\sigma_{\theta}\right]$.

The $\left[\sigma_{\theta}\right]$ is closely related to $\left\langle\delta_{z} \theta\right\rangle$ (Fig. 4a), presumably because nonturbulent (submesoscale) vertical motions generate local changes of $\theta$ that are proportional to $\left\langle\delta_{z} \theta\right\rangle$. In addition, stratification directly contributes to spatial variations of $\theta$ due to variations of surface elevation. Because $\langle U\rangle$ and $\left\langle\delta_{z} \theta\right\rangle$ are inversely correlated, their influences on $\left[\sigma_{\theta}\right]$ cannot be completely separated. For higher wind speeds, warm-air advection appears to maintain finite $\left\langle\delta_{z} \theta\right\rangle$, which becomes a function of wind direction at the SCP site (Mahrt 2017a).

\section{b. Spatial variation of the wind vector}

The spatial variation of horizontal velocity fluctuations across the network is written as

$$
\sigma_{V} \equiv \sqrt{\left(\sigma_{u}^{2}+\sigma_{v}^{2}\right)}
$$

For moderate and lower wind speeds at the SCP site, $\langle U\rangle<$ $5 \mathrm{~m} \mathrm{~s}^{-1}, \sigma_{V}$ is relatively independent of $\langle U\rangle$ (Fig. 4b). The $\sigma_{V}$ increases with increasing $\langle U\rangle$ for larger $\langle U\rangle$ (Fig. 4b) partly due to greater shear, probably enhanced by interaction of the flow with the topography. For low wind speeds, $\sigma_{V}$ increases with increasing $\left\langle\delta_{z} \theta\right\rangle$ (not shown), which explains the large variation of $\sigma_{V}$ for individual points with low wind speeds (Fig. 4b). The ratio $\sigma_{V} /\langle U\rangle$ (not shown) decreases with increasing $\langle U\rangle$ for all values of $\langle U\rangle$.

We construct a nondimensional ratio that represents the relative importance of horizontal variations of temperature with respect to the horizontal variations of the wind field

$$
R_{\sigma} \equiv \frac{\sqrt{g z}}{\Theta} \frac{\sigma_{\theta}}{\sigma_{V}} .
$$
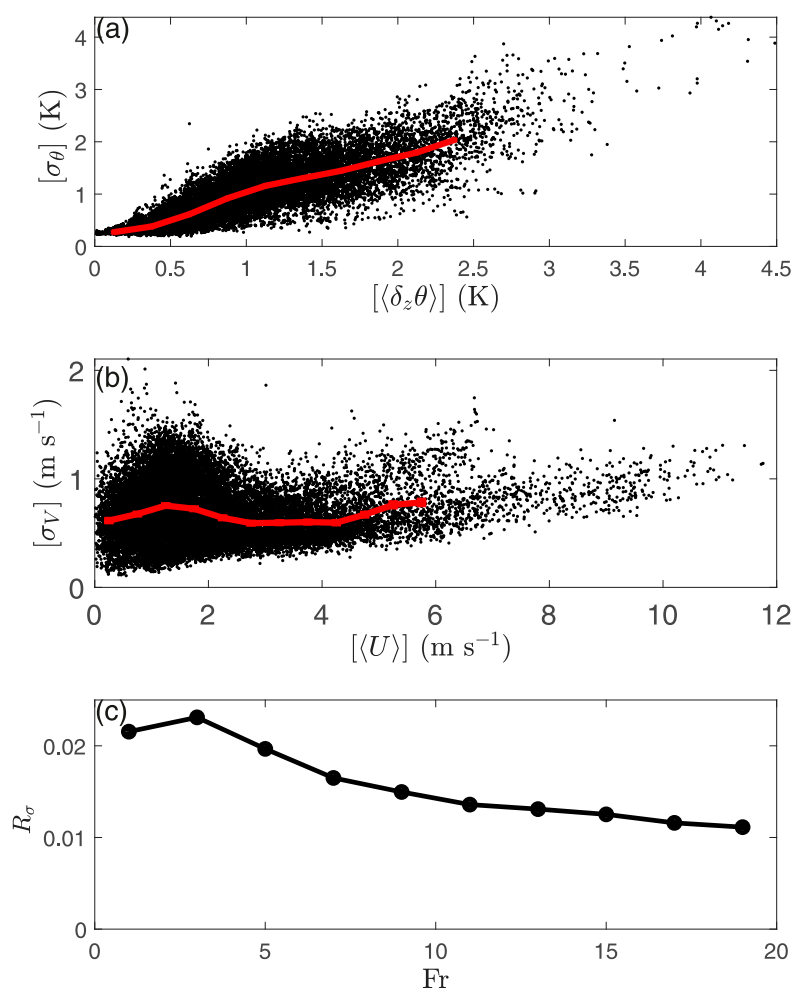

FIG. 4. (a) The horizontal variation of temperature $\sigma_{\theta}$ as a function of $\left\langle\delta_{z} \theta\right\rangle$ at the SCP network where dots indicate individual 1-min values. (b) The $\sigma_{V}$ as a function of $\langle U\rangle$. (c) The scaled ratio of $\left[\sigma_{\theta}\right]$ to $\left[\sigma_{V}\right]$, or $R_{\sigma}$, as a function of the Froude number Fr. The red lines in (a) and (b) are bin averages. Standard errors are not shown in this study because they are generally too small to visualize given the large number of data points. As a result of typical nonstationarity for stable conditions and corresponding lack of independence, the standard error can seriously underestimate the true uncertainty.

This ratio is expected to be small for windy conditions and large for low wind speeds and significant stratification, that is, inversely related to Fr as observed in Fig. 4c. The ratio $R_{\sigma}$ decreases with increasing Fr (Fig. 4c), probably because mixing generated by higher wind speeds reduces the horizontal temperature variations more effectively than the horizontal variations of the wind field. Thus, the horizontal variations of the wind vector decrease less with increasing Fr when compared with the greater decrease of the horizontal variations of temperature. Relating variables to $U$ instead of Fr explains almost as much variance as $\mathrm{Fr}$, partly because the stratification is significantly inverse correlated with $\langle U\rangle$. The other three networks analyzed in this study all show that the ratio $R_{\sigma}$ decreases with increasing $\langle U\rangle$ because $\sigma_{\theta}$ decreases systematically with increasing $\langle U\rangle$ while $\sigma_{V}$ does not.

\section{c. Joint relation of $\sigma_{\theta}$ to $\left\langle\delta_{z} \theta\right\rangle$ and $\langle U\rangle$ for $S C P$}

The horizontal variation of $\theta$ increases with the strength of the stratification (Fig. 4a). Vertical motions associated with topography and transient submesoscale motions more effectively generate temperature variations with significant 


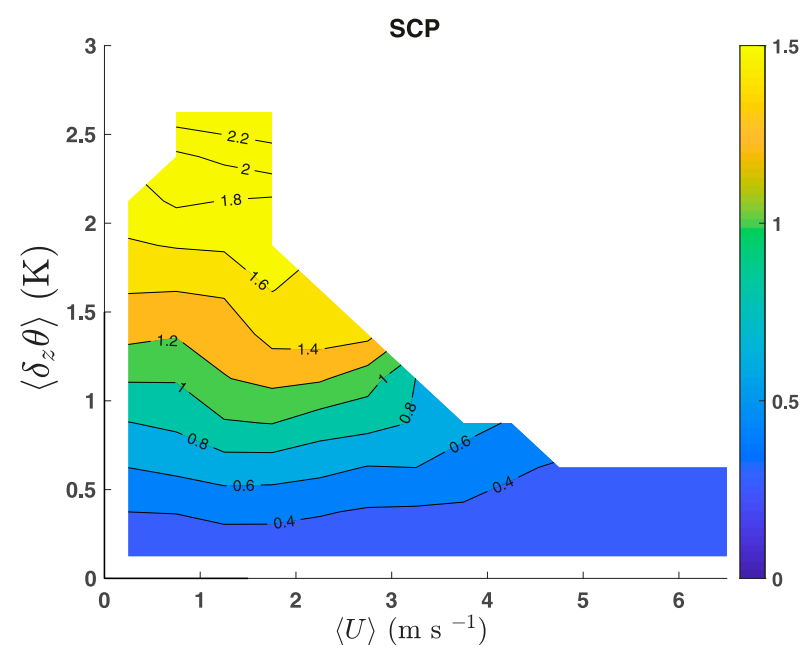

FIG. 5. The bivariate distribution of the horizontal temperature variation $\sigma_{\theta}$ in terms of stratification $\left\langle\delta_{z} \theta\right\rangle$ and $\langle U\rangle$. The color bar identifies the composited $\sigma_{\theta}(\mathrm{K})$, which is also labeled on the isolines of the plot.

stratification. The $\sigma_{\theta}$ approaches about $0.25 \mathrm{~K}$ as $\left\langle\delta_{z} \theta\right\rangle$ approaches zero. This limit is characterized by high wind speeds where both $\left\langle\delta_{z} \theta\right\rangle$ and $\left\langle\sigma_{\theta}\right\rangle$ become small. The $\sigma_{\theta}$ does not vanish partly because cooler air sometimes remains on the valley floor during periods of flow acceleration when the temperature lags changes of the wind field (Geiss and Mahrt 2015). Based on intercomparisons, instrumental offsets are thought to be $0.1 \mathrm{~K}$ or less for the SCP network and thus have little influence on $\left\langle\delta_{z} \theta\right\rangle$.

The bivariate distribution of the temperature variation $\sigma_{\theta}$, in terms of the stratification $\left\langle\delta_{z} \theta\right\rangle$ and $\langle U\rangle$, is shaped by the inverse dependence of $\left\langle\delta_{z} \theta\right\rangle$ on $\langle U\rangle$ (Fig. 5). Higher wind speeds generate more vertical mixing that reduces $\left\langle\delta_{z} \theta\right\rangle$. For $U<$ $2 \mathrm{~m} \mathrm{~s}^{-1}, \sigma_{\theta}$ is relatively independent of $U$, but increases rapidly with increasing $\left\langle\delta_{z} \theta\right\rangle$. Increasing $\sigma_{\theta}$ with increasing $\left\langle\delta_{z} \theta\right\rangle$ results from at least two different processes. The stratification $\left\langle\delta_{z} \theta\right\rangle$ reduces turbulent mixing that then promotes horizontal variation of temperature due to surface heterogeneity and topography. Second, nonturbulent vertical motions induce horizontal temperature changes that are proportional to the stratification. Figure 5 indicates that the increase of $\sigma_{\theta}$ with increasing $\left\langle\delta_{z} \theta\right\rangle$ is primarily associated with low wind speed. For $U>2 \mathrm{~m} \mathrm{~s}^{-1},\left\langle\delta_{z} \theta\right\rangle$ becomes small and $\sigma_{\theta}$ becomes less dependent on $\left\langle\delta_{z} \theta\right\rangle$. In this wind regime, $\sigma_{\theta}$ decreases very slowly with increasing $\langle U\rangle$ (Fig. 5). Because higher wind speeds are associated with fewer points, $\sigma_{\theta}$ for the entire dataset is dominated by lower wind speeds and thus increases with increasing $\left\langle\delta_{z} \theta\right\rangle$.

\section{d. Dependence of $\sigma_{\theta}$ on stability}

The horizontal temperature variation, $\sigma_{\theta}$, is significantly larger at the Perdigão network than at the SCP network (Fig. 6a) presumably because of greater sheltering associated with the steeper side slopes. The Obukhov length $L$ is used in Fig. 6a as a general indicator of stability to compensate for the
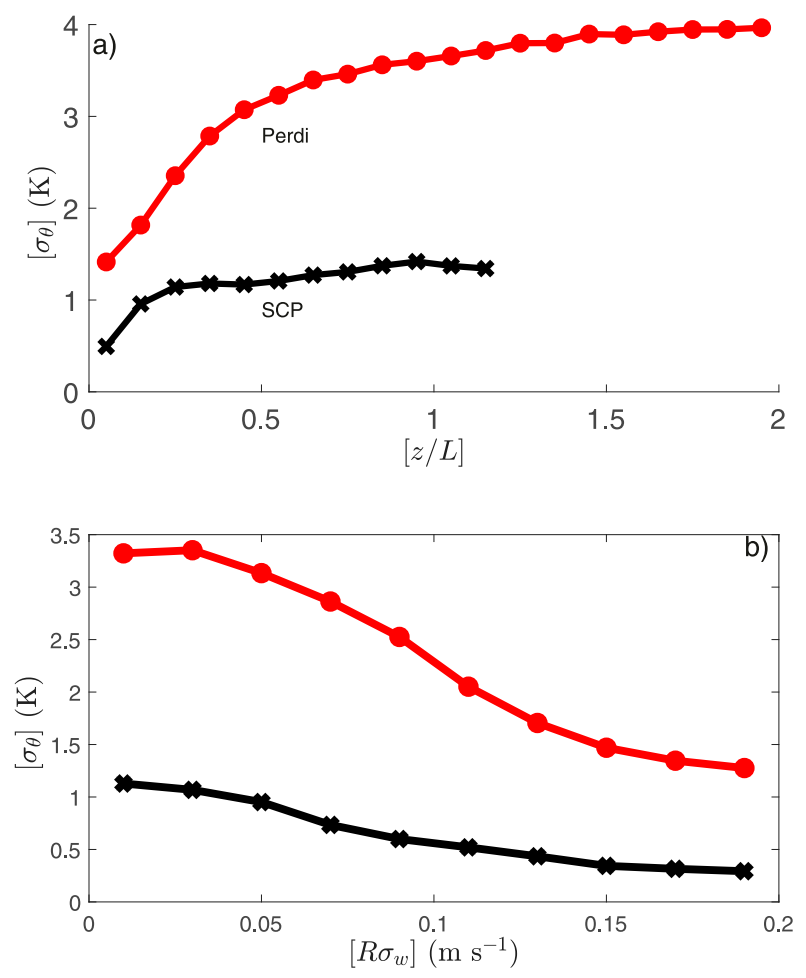

FIG. 6. The $\left[\sigma_{\theta}\right]$ as a function of (a) $[z / L]$ based on spatially averaged fluxes and (b) the modified standard deviation of the turbulent fluctuations of the vertical velocity $\left[R \sigma_{w}\right]$ [Eq. (5)] based on area-averaged quantities for the SCP network (black crosses) and the Perdigão network (red circles).

lack of a uniform measure of the stratification between networks. $\sigma_{\theta}$ is smallest for near-neutral conditions (Fig. 6a). $\sigma_{\theta}$ increases with increasing $z / L$ but then saturates without further increase. Perhaps the significant increases of $\sigma_{\theta}$ occurs with formation of the cold pool, but further increase of $z / L$ corresponds to only small increases of cold-pool strength and $\sigma_{\theta}$. The range of $z / L$ is greater at the Perdigão network, but the range of $\left\langle R \sigma_{w}\right\rangle$ is similar between the two sites (Fig. 6b). $\sigma_{\theta}$ decreases with increasing $\left\langle R \sigma_{w}\right\rangle$ for both networks probably because greater turbulent mixing and greater vertical coupling reduce horizontal temperature variations.

\section{The behavior of $\sigma_{\theta}$ contrasted between the four networks}

We now contrast the dependence of $\left[\sigma_{\theta}\right]$ on $[\langle U\rangle]$ for the four networks. The behavior of $\sigma_{\theta}$ varies significantly between networks. For the lowest wind speeds, $\left[\sigma_{\theta}\right]$ is largest for the Pedras Altas (cyan squares, Fig. 7) and Perdigão (red circles) networks, about $3 \mathrm{~K}$. The large average spatial variation is partly due to the substantial and well organized terrain. However, $\left[\sigma_{\theta}\right]$ decreases rapidly with increasing $[\langle U\rangle]$ at the Pedras Altas site. Because the Pedras Altas network does not include the strongest part of the cold pool at the bottom of the slope, modest wind speeds that reduce the temperature gradient on the slope also reduces $\left[\sigma_{\theta}\right]$ for this network. The strong 


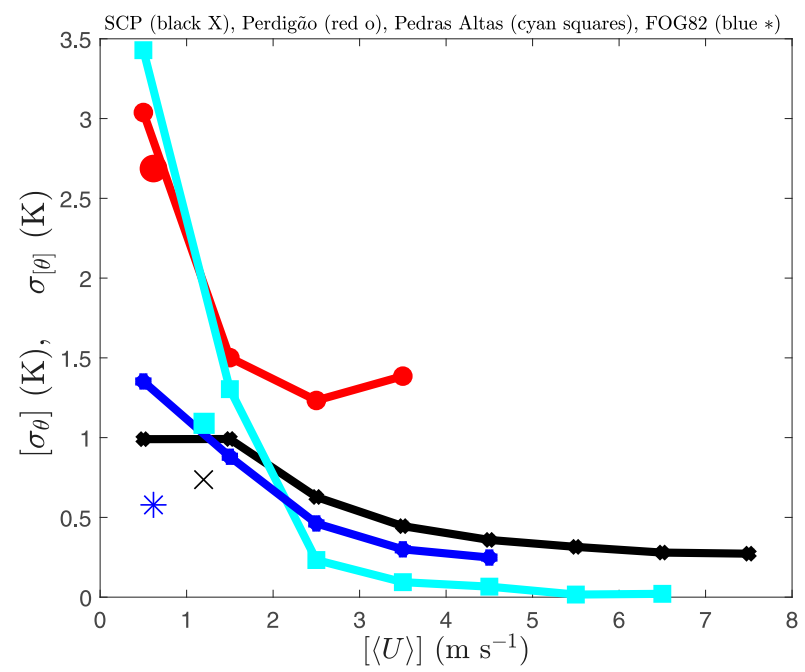

FIG. 7. The $\left[\sigma_{\theta}\right]$ as a function of $[\langle U\rangle]$ for the SCP network (black crosses), the Pedras Atlas network (cyan squares), the Perdigão network (red circles), and the FOG-82 network (blue asterisks). The individual symbols are values of $\sigma_{\theta}$ based on experimentaveraged values of $\theta$ for each station $\left(\sigma_{[\theta]}\right)$ using only cases with low wind speed $\left(\langle U\rangle<2 \mathrm{~m} \mathrm{~s}^{-1}\right)$.

sheltering in the valley by the steep slopes in the Perdigão network often protects the cold pool even for more significant wind speeds. Thus, $\left[\sigma_{\theta}\right]$ decreases more slowly with increasing wind speed relative to the Pedras Altas network. Spatial temperature variability at the Perdigão site shows no obvious decrease with wind speed for speeds greater than about $1 \mathrm{~m} \mathrm{~s}^{-1}$, while $\left[\sigma_{\theta}\right]$ for the other networks continues to decrease, corresponding to elimination of cold pools. $\left[\sigma_{\theta}\right]$ for the FOG-82 network (blue asterisks, Fig. 7) is similar to that for the SCP network (black X's). The FOG-82 network includes higher amplitude terrain than in the SCP network, but the terrain is more disorganized with heterogenous vegetation and a couple of the stations are surrounded by suburban settings.

Averaging $\theta$ over the entire field program produces a single "climatic" value of the temperature variability, $\sigma_{[\theta]}$, which is generated primarily by topography and heterogeneity. The averaging over the field program reduces the contribution of the nonstationary motions and the between-night variations. $\sigma_{[\theta]}$ is computed for low wind speeds $\left(\langle U\rangle<2 \mathrm{~m} \mathrm{~s}^{-1}\right)$ and is indicated by one symbol for each network in Fig. 7. The variation of the experiment average $\sigma_{[\theta]}$ for low wind speeds accounts for a significant fraction of the spatial variation of temperature $\left[\sigma_{\theta}\right]$. If the temperature pattern was constant throughout the field program, $\sigma_{[\theta]}$ would be equal to $\left[\sigma_{\theta}\right]$. For the lowest wind speeds, the climatic average, $\sigma_{[\theta]}$, is about 0.6$1.1 \mathrm{~K}$ for the SCP, Pedras Altas, and FOG-82 networks, and almost $3 \mathrm{~K}$ for the deeper Perdigão valley.

The temperature variation $\sigma_{\theta}$ depends only weakly on wind direction for the SCP network, although wind directions between $30^{\circ}$ and $250^{\circ}$ are uncommon (not shown). Some effect of wind direction is evident in terms of local temperature variations within the SCP network (section 7). Evidently, such variations do not lead to large changes of the overall dependence of $\sigma_{\theta}$ on wind direction. For the Perdigão network, $\sigma_{\theta}$ is relatively independent of the ridgetop wind direction where the ridgetop winds almost always have a significant cross-valley component. The sheltered very weak airflow on the valley floor appears to be decoupled from the ridgetop winds because under relatively clear skies the cold-air pool generally survives, regardless of the ridgetop wind direction or speed.

The temperature variation $\sigma_{\theta}$ is greater at the Pedras Altas site (north-facing slope) with northerly flow near the top of the slope. Wind speeds decrease farther down the slope. Evidently, the northerly flow overrides the colder air lower on the slope and connects with the surface higher on the slope. For southerly downslope winds near the top of the slope, the winds are roughly the same speed and direction along the slope that could be influenced by cold-air drainage without the cold-air pool extending up to the network.

The experiment-averaged value of $\sigma_{\theta}$ is about $1 \mathrm{~K}$ for the SCP, Pedras Altas, and FOG-82 networks, and about $3 \mathrm{~K}$ for the deeper Perdigão valley. Extreme values (Fig. 8) reach about $4.5 \mathrm{~K}$ for the SCP and FOG82 networks, $6.3 \mathrm{~K}$ for Perdigão network and $7.3 \mathrm{~K}$ for the Pedras Altas network. The large values of $\sigma_{\theta}$ for the Pedras Altas network are partly due to a few fronts of unknown scale and origin. The large number of small values of $\sigma_{\theta}$ is due to relatively windy or cloudy conditions that lead to small temperature variation on the slope even when the cold pool survives below the network. The skewness of the distribution is strongly positive (1.8). The frequency distributions are also positively skewed for the SCP (1.1) and FOG-82 (0.4) networks. The exact values of the skewness are not statistically significant.

The distribution of $\sigma_{\theta}$ for the Perdigão network is lightly skewed negative $(-0.2)$ in contrast to the other three networks. The maximum probability occurs at a relatively large value of $\sigma_{\theta}$ for the Perdigão network corresponding to well defined valley cold pools. Because of the lack of independence of the data samples due to nonstationarity, significance tests may be unreliable and the above skewness values are only rough estimates. Evaluation of extreme value statistics is marginal without a longer dataset and is not pursued here.

With large values of $\sigma_{\theta}$, the unknown temperature at an arbitrary point might be much different from the temperature at the nearest measurement station in contrast to windier conditions when $\sigma_{\theta}$ is smaller. The deviation of $\theta$ at a fixed station from the network average $\theta$ can exceed $10 \mathrm{~K}$ even at the SCP site. Two-station differences of $\theta$ can be much larger than $\sigma_{\theta}$, as would occur with temperature differences between the valley bottom and farther up the slope. Stations closer to each other generally have smaller temperature differences. The maximum two-station difference of average $[\theta]$ is 2-3 times the average $\left[\sigma_{\theta}\right]$. The maximum values of $\sigma_{\theta}$ would increase with increasing duration of the field program.

\section{Local horizontal variation of temperature}

Much of the horizontal variability of temperature is related to formation of cold air in the valley and tributary gullies, lee turbulence, local thin drainage flows and surface heterogeneity of the surface. We now focus on these phenomena in terms of temperature differences between specific stations rather than 

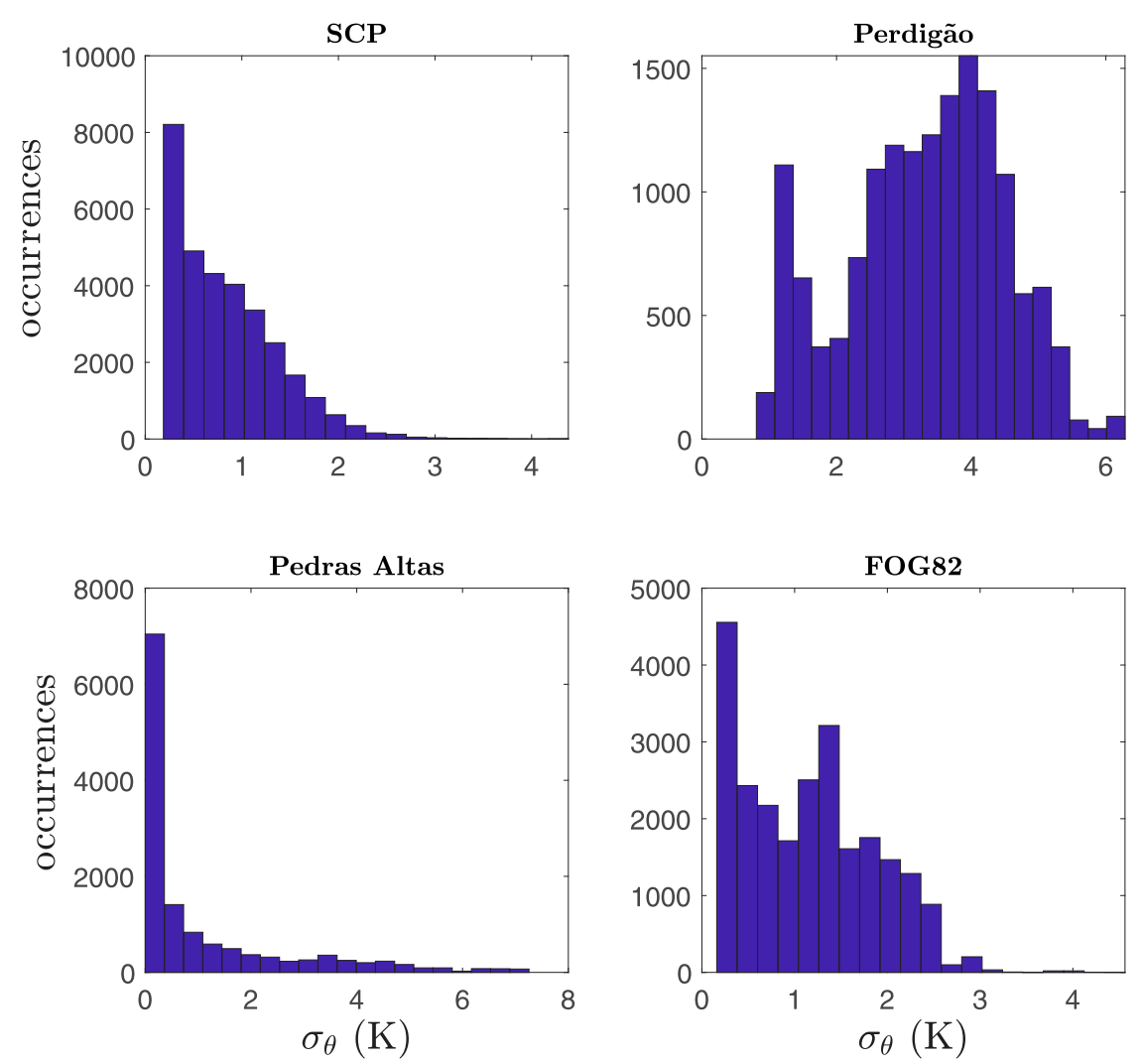

FIG. 8. Histograms of $\sigma_{\theta}$ for the four networks. The range of the $x$ axis extends to the largest values of $\sigma_{\theta}$, although the number of cases may be too small to visualize.

the temperature variation for the entire network $\sigma_{\theta}$. We investigate only the SCP and Perdigão networks that sample a single valley system and include turbulence measurements.

We first construct temperature differences to characterize the valley cold pool. Such temperature differences only approximate the valley temperature characteristics that may be quite complex. We evaluate a cold-pool index (CPI) defined as (Bodine et al. 2009)

$$
\mathrm{CPI} \equiv \theta_{\text {upslope }}-\theta_{\text {valley }},
$$

where $\theta_{\text {upslope }}$ is nominally the highest available station on the valley side slope. The $\theta_{\text {upslope }}$ for SCP is computed as an average of $\theta$ at stations A9 (north shoulder) and A14 (south shoulder) located in Fig. 1. The valley temperature $\theta_{\text {valley }}$ is computed from the average of $\theta$ for stations A8 and A11 on the valley floor. The $[\mathrm{CPI}]$ reaches a maximum value of about $2 \mathrm{~K}$ at $[\langle U\rangle] \approx 1.5 \mathrm{~m} \mathrm{~s}^{-1}$ (Fig. 9a, black circles). Lower wind speeds are associated with increased frequency of cloud cover and decreasing magnitude of the net radiation (not shown) and thus smaller [CPI]. For higher wind speeds, the [CPI] decreases due to increasing mixing and decreasing stratification. [CPI] asymptotically approaches a value of $0.35 \mathrm{~K}$ for the highest wind speeds. This residual value of [CPI] might be due partly to nonstationarity of the wind field and lagging temperature. With the onset of higher winds, elimination of the cold pool requires a finite amount of time as found in Geiss and Mahrt (2015) for the SCP network.
The temperature does not increase significantly up the south shoulder because the cold pool is often displaced toward the south by the northerly flow component (Fig. 10b), as examined in more detail by Mahrt (2017b) and Pfister et al. (2021a). If the upslope temperature is computed only from A9, where lee turbulence sometimes occurs (Mahrt 2017b; Pfister et al. 2021b), the maximum value of CPI increases from about 2 to $3 \mathrm{~K}$.

For the Perdigão network, $\theta_{\text {valley }}$ is chosen as the downvalley station [V07; (Fernando et al. 2019)] and $\theta_{\text {upslope }}$ is the average for the five ridgetop stations. Here, $[\langle U\rangle]$ is based on the speed of the vector average of the five ridgetop stations. The CPI for the Perdigão site (Fig. 9b, black circles) is about 4 times that for SCP most likely due to the relatively deep valley and steep side slopes. The CPI for the Perdigão network decreases only very slowly with increasing ridgetop winds until they reach about $4.5 \mathrm{~m} \mathrm{~s}^{-1}$ when the CPI begins to decrease significantly with further increase of the ridgetop wind speeds. The cold-pool index for the Perdigão network is also relatively decoupled from the ridgetop wind direction (not shown). These findings are similar to those of Daly et al. (2010) who found decoupling of the valley cold pools from the larger-scale flow observed at the top of the steep slopes in the Cascade Range.

\section{a. Variation of $\theta$ down the valley}

The down-valley variation of temperature has received little attention in the literature, partly because it is generally significantly smaller than the CPI and more difficult to assess. 

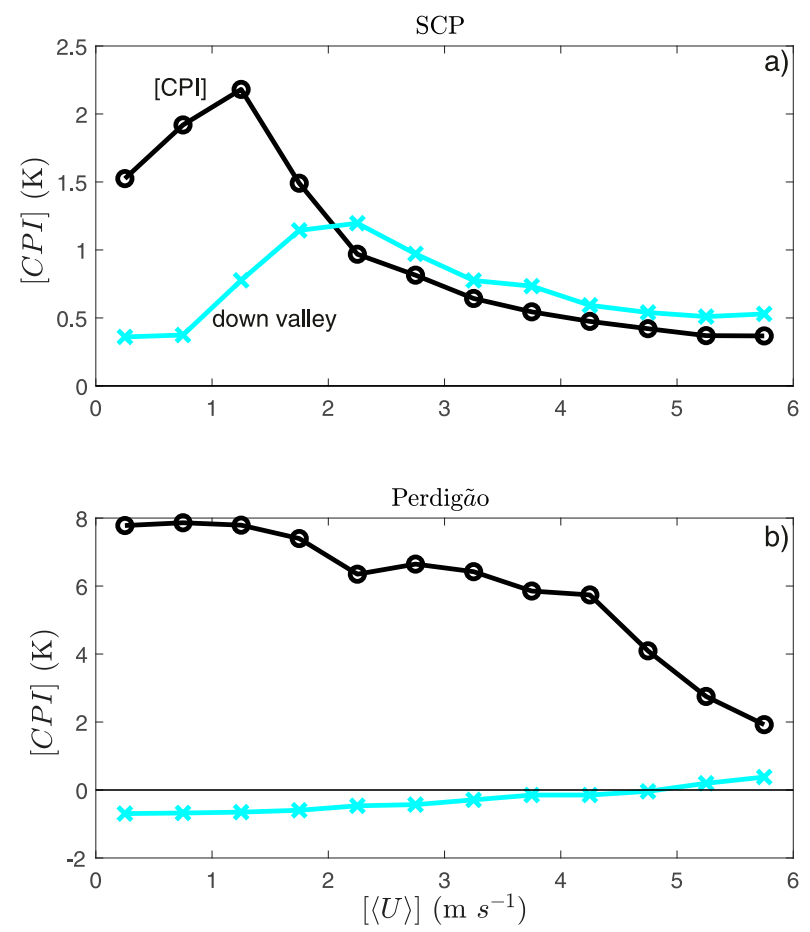

FIG. 9. The [CPI] (black circles) and the along-valley temperature difference $[\mathrm{DV}]$ (cyan crosses) as a function of $[\langle U\rangle]$ for (a) the SCP network and (b) the Perdigão network.

To estimate the temperature change down the valley, we compute the temperature difference in the down-valley direction, expressed as

$$
\mathrm{DV} \equiv \theta_{\text {downvalley }}-\theta_{\text {upvalley }} .
$$

For the SCP site, $\theta_{\text {upvalley }}$ is chosen as station A11 and $\theta_{\text {downvalley }}$ is A20. For Perdigão, the down-valley temperature difference is computed using the two stations on the valley floor, separated by a distance of $700 \mathrm{~m}$ and an elevation change of $10 \mathrm{~m}$.

For SCP, the temperature increases down the valley partly because the valley widens and the side slopes become shorter, which reduces the sheltering. Lundquist et al. (2008) revealed the potential importance of the change of temperature down the valley due to narrowing or widening of the valley. The down-valley temperature change reaches a maximum positive value of about $1.2 \mathrm{~K}$ for $[\langle U\rangle] \approx 2 \mathrm{~m} \mathrm{~s}^{-1}$ (Fig. 9a, cyan crosses). At the Perdigão site, the potential temperature decreases slowly down the valley (Fig. 9b, cyan crosses), although this temperature difference is small, particularly for wind speeds greater than $3 \mathrm{~m} \mathrm{~s}^{-1}$. The valley width does not change appreciably between the two valley stations (Fig. 2).

The potential temperature in the SCP network decreases from the upper end of the tributary gully (station A1) down to the upper end of the main valley (A8), as shown in Fig. 10a. Then the temperature increases abruptly between A8 and A11. Station A8 has the weakest average wind speed of the network, which might contribute to less mixing and more
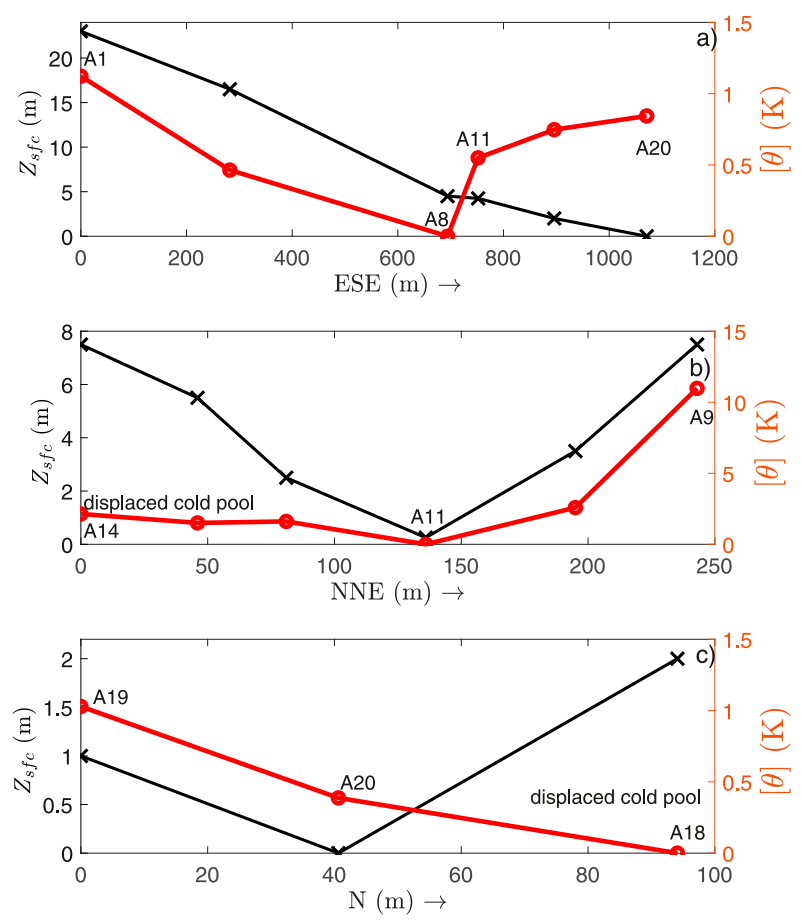

FIG. 10. (a) The transect of $[\theta]$ along the valley bottom (red circles), where $Z_{\text {sfc }}$ (black crosses) is the surface elevation and the up-valley end is on the left. The location of the stations is identified by the thin gray line in Fig. 1. (b) The transect of $[\theta]$ across the main valley, where the north shoulder is on the right. (c) The transect of $[\theta]$ across the valley in the down-valley region, where the north shoulder is on the right.

cooling. The cooling at A11 might be reduced by the frequent displacement of the cold pool by the northerly flow to south of the valley floor (Fig. 10b). The relatively higher temperatures farther down the valley (A20) are probably related to decreased sheltering in the wider valley with lower side slopes.

\section{b. Cross-valley asymmetry of $\theta$}

The horizontal distribution of temperature perpendicular to the valley axis can be asymmetric due to asymmetry of the terrain or displacement of the cold pool by cross-valley flow. This asymmetry of the temperature at the Perdigão site was difficult to isolate because of the influence of vegetation heterogeneity on the side slopes, which requires finer spatial resolution to resolve. Surface heterogeneity led to erratic variation of the temperature and wind speed with distance up the slope (not shown). The effect of lee turbulence and recirculation on the temperature of the upper slope (Menke et al. 2019) appeared to be potentially significant, but the results were not conclusive and are excluded from our analysis below.

The cross-valley index (CVI) measures the asymmetry of the temperature distribution across the valley using the surface air temperature on the opposing side slopes at approximately the same elevation. We write

$$
\mathrm{CVI} \equiv \theta_{\text {slope } 2}-\theta_{\text {slope } 1}
$$


For the SCP network, $\theta_{\text {slope } 2}$ is the temperature on the north shoulder of the valley (A9) and $\theta_{\text {slope } 1}$ is the temperature on the south shoulder of the valley (A14), both approximately $8 \mathrm{~m}$ above the valley floor. The cross-valley temperature difference is generally positive because the downwind south shoulder of the valley is normally colder than the north shoulder due to displacement of the cold pool by the northerly flow. Lee turbulence on the north shoulder (Mahrt 2017b; Pfister et al. 2021a) also contributes to this temperature asymmetry. The cross-valley index reaches a maximum value at an intermediate magnitude of $v$ from the north $\left(-3.5 \mathrm{~m} \mathrm{~s}^{-1}\right.$; Fig. 11), corresponding to a cross-valley temperature difference of about $2 \mathrm{~K}$. This is almost as large as the maximum value of [CPI] (Fig. 9a, black). For higher wind speeds, the temperature variation becomes small (left side of Fig. 11) partly because increased mixing reduces the horizontal variation of temperature. For lower values of the cross-valley wind speed, the wind vector is often more oblique to the valley and/or the temperature variations are controlled by other processes. The cross-valley temperature asymmetry [CVI] becomes small as the $v$ component vanishes but remains small positive, possibly because of lag of the temperature change with respect to changes of the wind direction.

The decreased sheltering of the valley at the down-valley station A20 seems to lead to a reversed cold-pool displacement into the upwind direction (Fig. 10c). Station A18 on the lower slope north of the valley is more directly sheltered than in the middle of valley floor. As a possible result, the coldest of the three stations on the north-south transect in Fig. 10c is on the slope just north of the valley floor. This upwind nonadvective displacement of the cold pool occurs mainly for $U>2 \mathrm{~m} \mathrm{~s}^{-1}$, when mixing is likely to become significant in the middle of the valley.

\section{c. Smaller cold pools}

We now examine CPI for different parts of the SCP valley system. The corresponding cold-pool indices increase systematically with increasing spatially averaged stratification (Fig. 12a), increasing horizontal variation of the temperature for the network $\sigma_{\theta}$ (Fig. 12b), and decreasing wind speed (Fig. 12c).

With strong stratification, the cold-pool index for the small tributary gulley (Fig. 12a, blue crosses) becomes as large as that for the main valley (black circles) despite the smaller depth of the tributary gulley, only about $30 \%$ of that for the main valley. This significant cold-pool index occurs despite the orientation of the tributary gully more in the northwest to southeast direction such that the tributary gulley is presumably more vulnerable to elimination of the cold pool by the common northwesterly flow. For the main valley and the tributary gulley, the observations do not extend to the top of the side slopes and thus underestimate CPI. The $[\mathrm{CPI}]$ for the down-valley stations $\{[\theta](\mathrm{A} 19)-[\theta](\mathrm{A} 20)\}$ (Figs. 12a-c, cyan squares) is significantly smaller than the [CPI] for the upland gully and main valley. Sheltering is less effective down-valley, probably because the valley is wider.

\section{Conclusions}

We examined the horizontal variation of the nocturnal surface air temperature by analyzing measurements from four

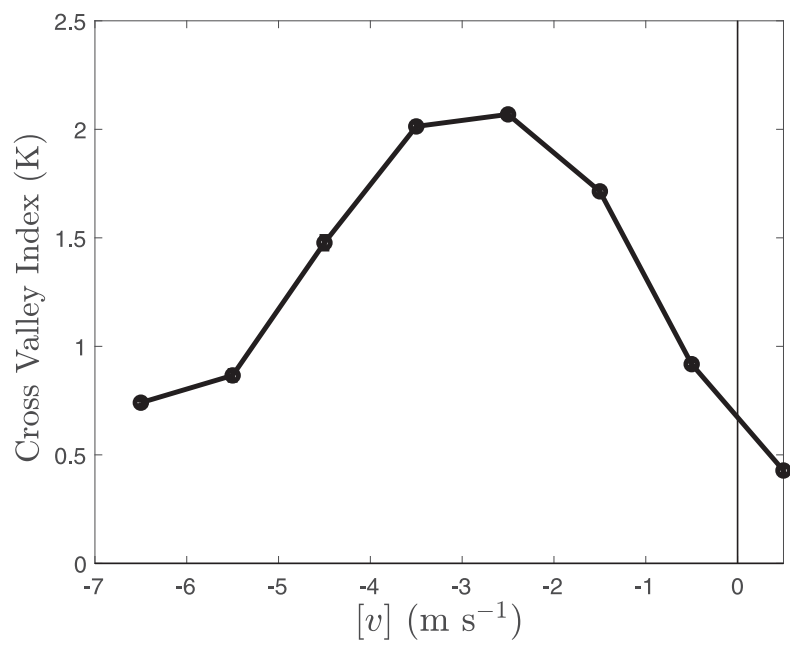

FIG. 11. The cross-valley temperature difference [CVI] between stations A9 and A14 at the SCP network as a function of the northerly wind component at station A9.

networks of stations, each with different topographical geometries that include a single shallow valley, a deep valley, a single slope, and multiple valleys of different horizontal scales. As found in previous studies, the surface elevation by itself is sometimes an unreliable predictor of the spatial variation of the nocturnal temperature. The response of the flow to the topography in our study includes traditional cold pools, displacement of the valley cold pool by the cross-valley flow, reversed (upwind) displacement of the cold pool associated with downward mixing, and lee turbulence. The choice of smaller subnetworks sometimes improved the relationship between the horizontal variation of the air temperature and the surface elevation.

For each network, we investigated the general relationship of the horizontal variation of temperature to the wind speed, wind direction, stratification, and turbulence. The horizontal variation of temperature varies with time during individual nights and between nights. The horizontal variation of temperature for the networks was represented by a simple standard deviation of temperature across the network $\sigma_{\theta}$, which decreases with increasing wind speed through increased turbulent mixing and vertical coupling. Based on the SCP network, the horizontal variation of the temperature increases systematically with increasing stratification. The stratification is the best single predictor of the horizontal variation of temperature, but it is not uniformly available between the four networks. The stratification tends to decrease with increasing wind speed although the exact dependence varies significantly between networks. For the Perdigão network, $\sigma_{\theta}$ decreases more slowly with increasing wind speed because the valley cold pool is sheltered by the relatively steep slopes.

Conceptually unifying the results from multiple networks is considerably more difficult than formulating results from an individual network, thus hampering a general prediction scheme for the spatial variation of temperature. Future networks should include at least fluxes and vertical structure of 

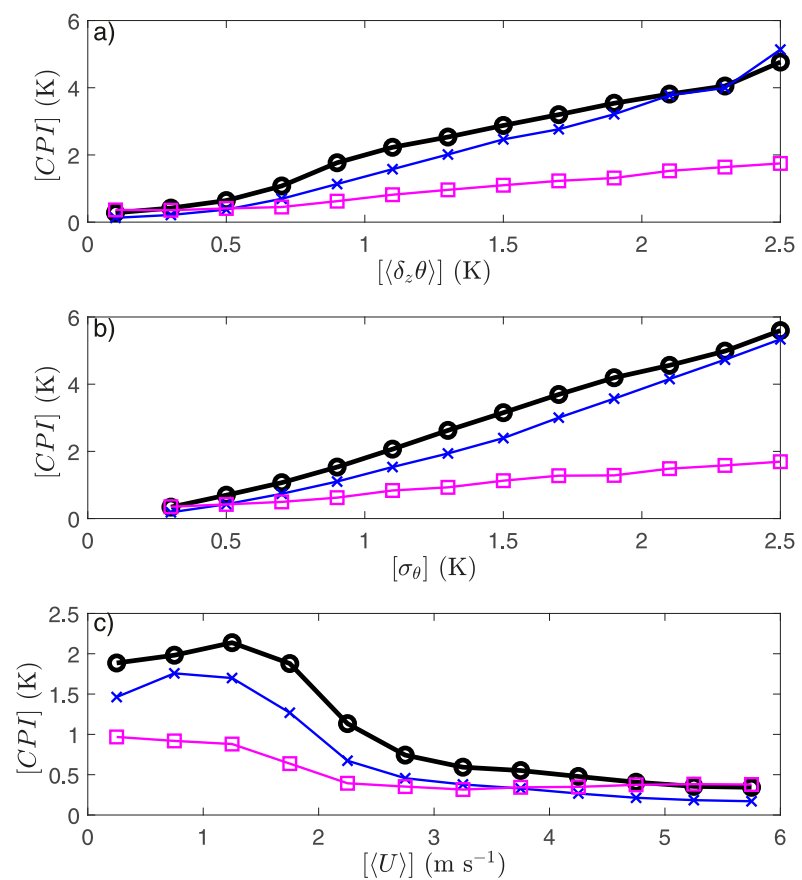

FIG. 12. The CPI based on two-point spatial differences of temperature in SCP as a function of: (a) the spatially averaged stratification, (b) the network standard deviation $\left[\sigma_{\theta}\right]$, and (c) the speed of the vector averaged wind $[\langle U\rangle]$. The two-point differences include [CPI] for the main valley [black open circles; Eq. (11)], $[\mathrm{CPI}]$ for the small tributary gulley $\{[\theta](\mathrm{A} 4)-[\theta](\mathrm{A} 5)\}$ (blue crosses), and the down-valley $[\mathrm{CPI}]\{[\theta](\mathrm{A} 19)-[\theta](\mathrm{A} 20)\}$ (magenta open squares). Quantities defining the $x$ axis for each panel refer to averages over the entire network.

temperature near the surface. In addition, fast-response temperature measurements with fine-scale horizontal resolution, such as fiber-optic distributed temperature sensing (Fernando et al. 2015; Zeeman et al. 2015; Pfister et al. 2021a), can provide essential information for improved understanding. A network over a flat and homogeneous area with regular station spacing would establish a valuable baseline for understanding the temperature variations in a relatively simple setting.

Acknowledgments. We gratefully acknowledge very helpful comments from the anonymous reviewers. Larry Mahrt is funded by Grant AGS 1945587 from the U.S. National Science Foundation. Otávio Acevedo is supported by the Brazilian Conselho Nacional de Desenvolvimento Cientifico e Tecnológico (CNPq) and Comissăo de Aperfeiçoamento de Pessoal de Ensino Superior (CAPES). Harindra Fernando was supported by NSF Award AGS-192155. We gratefully acknowledge Dave Fitzjarrald for the FOG-82 data and helpful comments on our study. The Earth Observing Laboratory of the National Center for Atmospheric Research provided the SCP and Perdigão measurements. Emily Moynihan at BlytheVisual LLC created Fig. 1.

Data availability statement. The SCP data can be obtained from https://data.eol.ucar.edu/project/385. The Perdigão data are accessed at https://www.eol.ucar.edu/field_projects/Perdigão or https://doi.org/10.26023/31GR-H228-A20Q. At this time, the FOG-82 and Pedras Altas data are not yet accessible.

\section{REFERENCES}

Abraham, C., and A. Monahan, 2020: Spatial dependence of stably stratified nocturnal boundary-layer regimes in complex terrain. Bound.-Layer Meteor., 177, 19-47, https://doi.org/10.1007/ s10546-020-00532-x.

Acevedo, O., and D. Fitzjarrald, 2001: The early evening surfacelayer transition: Temporal and spatial variability. J. Atmos. Sci., 58, 2650-2667, https://doi.org/10.1175/1520-0469(2001) 058<2650:TEESLT $>2.0 . \mathrm{CO} ; 2$.

—, and — 2003: In the core of the night—Effect of intermittent mixing on a horizontally heterogeneous surface. Bound.-Layer Meteor., 106, 1-33, https://doi.org/10.1023/A:1020824109575.

Angevine, W., J. M. Edwards, M. Lothon, M. A. LeMone, and S. R. Osborne, 2020: Transition periods in the diurnally-varying atmospheric boundary layer over land. Bound.-Layer Meteor., 177, 205-223, https://doi.org/10.1007/s10546-020-00515-y.

Banta, R., L. Olivier, W. Neff, D. Levinson, and D. Ruffieux, 1995: Influence of canyon-induced flows on flow and dispersion over adjacent plains. Theor. Appl. Climatol., 52, 27-42, https:// doi.org/10.1007/BF00865505.

Bodine, D., P. Klein, S. Arms, and A. Shapiro, 2009: Variability of surface air temperature over gently sloped terrain. J. Appl. Meteor., 48, 1117-1141, https://doi.org/10.1175/2009JAMC1933.1.

Bou-Zeid, E., W. Anderson, G. G. Katul, and L. Mahrt, 2020: The persistent challenge of surface heterogeneity in boundarylayer meteorology: A review. Bound.-Layer Meteor., 177, 227245, https://doi.org/10.1007/s10546-020-00551-8.

Connolly, A., F. K. Chow, and S. W. Hoch, 2021: Nested large-eddy simulations of the displacement of a cold-air pool by lee vortices. Bound.-Layer Meteor., 178, 91-118, https://doi.org/ 10.1007/s10546-020-00561-6.

Daly, C., D. R. Conklin, and M. H. Unsworth, 2010: Local atmospheric decoupling in complex topography alters climate change impacts. Int. J. Climatol., 30, 1857-1864, https:// doi.org/10.1002/joc.2007.

De Wekker, S. F. J., and C. D. Whiteman, 2006: On the time scale of nocturnal boundary layer cooling in valleys and basins and over plains. J. Appl. Meteor. Climatol., 45, 813-820, https:// doi.org/10.1175/JAM2378.1.

Fernando, H. J. S., 2010: Fluid dynamics of urban atmospheres in complex terrain. Annu. Rev. Fluid Mech., 42, 365-389, https:// doi.org/10.1146/annurev-fluid-121108-145459.

- , and Coauthors, 2015: The MATERHORN: Unraveling the intricacies of mountain weather. Bull. Amer. Meteor. Soc., 96, 1945-1967, https://doi.org/10.1175/BAMS-D-13-00131.1.

— J. K. Lundquist, and S. Oncley, 2017: Monitoring wind in Portugal's mountains down to microscales. Eos, 98, https:// doi.org/10.1029/2017EO074745.

_ , and Coauthors, 2019: The Perdigão: Peering into microscale details of mountain winds Bull. Amer. Meteor. Soc., 100, 799-819, https://doi.org/10.1175/BAMS-D-17-0227.1.

Geiss, A., and L. Mahrt, 2015: Decomposition of spatial structure of nocturnal flow over gentle terrain. Bound.-Layer Meteor., 156, 337-347, https://doi.org/10.1007/s10546-015-0043-7.

Grachev, A., E. Andreas, C. Fairall, P. Guest, and P. Persson, 2007: SHEBA flux-profile relationships in the stable atmospheric boundary layer. Bound.-Layer Meteor., 124, 315-333, https:// doi.org/10.1007/s10546-007-9177-6. 
Guerra, V. S., O. C. Acevedo, L. E. Medeiros, P. E. S. Oliveira, and D. M. Santos, 2018: Small-scale horizontal variability of mean and turbulent quantities in the nocturnal boundary layer. Bound.-Layer Meteor., 169, 395-411, https://doi.org/10.1007/ s10546-018-0381-3.

Jemmett-Smith, B. C., A. N. Ross, P. F. Sheridan, J. K. Hughes, and S. B. Vosper, 2019: A case-study of cold-air pool evolution in hilly terrain using field measurements from COLPEX. Quart. J. Roy. Meteor. Soc., 145, 1290-1306, https://doi.org/10.1002/ qj.3499.

Lapworth, A., and S. R. Osborne, 2020: The nocturnal wind speed and sensible heat flux over flat terrain. Bound.-Layer Meteor., 176, 401-413, https://doi.org/10.1007/s10546-020-00534-9.

Lehner, M., C. D. Whiteman, S. Hoch, D. Jensen, E. Pardyjak, L. S. Leo, S. D. Sabatino, and H. Fernando, 2015: A case study of the nocturnal boundary-layer evolution on a slope at the foot of a desert mountain. J. Appl. Meteor. Climatol., 54, 732-751, https://doi.org/10.1175/JAMC-D-14-0223.1.

,-- , and M. Doringer, 2017: Inversion build-up and cold-air outflows in a small alpine sinkhole. Bound-Layer Meteor., 163, 497-522, https://doi.org/10.1007/s10546-017-0232-7.

LeMone, M., I. Kyoko, R. Grossman, and M. Rotach, 2003: Horizontal variability of $2-\mathrm{m}$ temperature at night during CASES-97. J. Atmos. Sci., 60, 2431-2449, https://doi.org/ 10.1175/1520-0469(2003)060<2431:HVOMTA > 2.0.CO;2.

Leo, L. S., H. J. S. Fernando, and D. Sabatino, 2015: Near-surface flow in complex terrain with coastal and urban influence. Environ. Fluid Mech., 15, 349-372, https://doi.org/10.1007/ s10652-013-9327-y.

Lu, W., and S. Zhong, 2014: A numerical study of a persistent cold air pool episode in the Salt Lake Valley, Utah. J. Geophys. Res., 119, 1733-1752, https://doi.org/10.1002/2013JD020410.

Lundquist, J., N. Pepping, and C. Rochford, 2008: Automated algorithm for mapping regions of cold-air pooling in complex terrain. J. Geophys. Res., 113, D22107, https://doi.org/10.1029/ 2008JD009879.

Mahrt, L., 2017a: Heat flux in the strong-wind nocturnal boundary layer. Bound.-Layer Meteor., 163, 161-177, https://doi.org/ 10.1007/s10546-016-0219-9.

— $2017 \mathrm{~b}$ : Lee mixing and nocturnal structure over gentle terrain. J. Atmos. Sci., 74, 1989-1999, https://doi.org/10.1175/ JAS-D-16-0338.1.

— Climatol., 54, 339-351, https://doi.org/10.1175/JAMC-D-140204.1.

—_, and C. K. Thomas, 2016: Surface stress with non-stationary weak winds and stable stratification. Bound.-Layer Meteor., 159, 3-21, https://doi.org/10.1007/s10546-015-0111-z.

,,-- S. Richardson, N. Seaman, D. Stauffer, and M. Zeeman, 2013: Non-stationary generation of weak turbulence for very stable and weak-wind conditions. Bound.-Layer Meteor., 147, 179-199, https://doi.org/10.1007/s10546-012-9782-x.

Medeiros, D. G., and D. Fitzjarrald, 2015: Stable boundary layer in complex terrain. Part II: Geometrical and sheltering effects on mixing. J. Appl. Meteor. Climatol., 54, 170-188, https://doi.org/ 10.1175/JAMC-D-13-0346.1.

Menke, R., N. Vasiljević, J. Mann, and J. K. Lundquist, 2019: Characterization of flow recirculation zones at the Perdigão site using multi-lidar measurements. Atmos. Chem. Phys., 19, 2713-2723, https://doi.org/10.5194/acp-19-2713-2019.

Pfister, L., A. Sigmund, J. Olesch, and C. K. Thomas, 2017: Nocturnal near-surface temperature but not flow dynamics, can be predicted by microtopography in a mid-range mountain valley. Bound.-Layer Meteor., 165, 333-348, https://doi.org/ 10.1007/s10546-017-0281-y.

- C. Sayde, J. Selker, L. Mahrt, and C. K. Thomas, 2019: Classifying the nocturnal atmospheric boundary layer into temperature and flow regimes. Quart. J. Roy. Meteor. Soc., 145, 1515-1534, https://doi.org/10.1002/qj.3508.

, K. Lapo, L. Mahrt, and C. K. Thomas, 2021a: Thermal submesoscale motions in the nocturnal stable boundary layer. Part 1: Detection and mean statistics. Bound.-Layer Meteor., 180, 187-202, https://doi.org/10.1007/s10546-021-00618-0.

$-, \ldots,-$, and $-2021 \mathrm{~b}$ : Thermal submeso motions in the nocturnal stable boundary layer. Part 2: Generating mechanisms and implications. Bound.-Layer Meteor., 180, 203-224, https://doi.org/10.1007/s10546-021-00619-z.

Sheridan, P., S. B. Vosper, and A. R. Brown, 2013: Characteristics of cold pools observed in narrow valleys and dependence on external conditions. Quart. J. Roy. Meteor. Soc., 140, 715-728, https://doi.org/10.1002/qj.2159.

- _ _ , and S. Smith, 2018: A physically based algorithm for downscaling temperature in complex terrain. J. Appl. Meteor. Climatol., 57, 1907-1929, https://doi.org/10.1175/JAMC-D-170140.1.

Smith, D. K. E., I. A. Renfrew, S. R. Dorling, J. D. Price, and I. A. Boutle, 2020: Sub-km scale numerical weather prediction model simulations of radiation fog. Quart. J. Roy. Meteor. Soc., 147, 746-763, https://doi.org/10.1002/qj.3943.

Staebler, R., and D. Fitzjarrald, 2004: Observing subcanopy $\mathrm{CO}_{2}$ advection. Agric. For. Meteor., 122, 139-156, https://doi.org/ 10.1016/j.agrformet.2003.09.011.

Stiperski, I., and M. W. Rotach, 2016: On the measurement of turbulence over complex mountainous terrain. Bound.-Layer Meteor., 159, 97-121, https://doi.org/10.1007/s10546-015-0103-z. van den Bossche, M., and S. F. J. De Wekker, 2018: Representativeness of wind measurements in moderately complex terrain. Theor. Appl. Climatol., 135, 491-504, https:// doi.org/10.1007/s00704-018-2402-z.

Vassallo, D., R. Krishnamurthy, R. Menke, and H. Fernando, 2021: Observations of stably stratified flow through a microscale gap. J. Atmos. Sci., 78, 189-208, https://doi.org/10.1175/JASD-20-0087.1.

Vosper, S. B., J. K. Hughes, A. P. Lock, P. F. Sheridan, A. N. Ross, B. Jemmett-Smith, and A. R. Brown, 2013: Cold-pool formation in narrow valleys. Quart. J. Roy. Meteor. Soc., 140, 699-714, https://doi.org/10.1002/qj.2160.

Whiteman, C. D., T. Haiden, B. Pospichal, S. Eisenbach, and R. Steinacker, 2004: Minimum temperatures, diurnal temperature ranges, and temperature inversions in limestone sinkholes of different sizes and shapes. J. Appl. Meteor., 43, 1224-1236, https://doi.org/10.1175/1520-0450(2004)043<1224: MTDTRA $>2.0 . \mathrm{CO} ; 2$.

Zeeman, M. J., J. S. Selker, and C. Thomas, 2015: Near-surface motion in the nocturnal, stable boundary layer observed with fibre-optic distributed temperature sensing. Bound.-Layer Meteor., 154, 189205, https://doi.org/10.1007/s10546-014-9972-9.

Zhong, S., C. D. Whiteman, X. Bian, W. J. Shaw, and J. M. Hubbe, 2001: Meteorological processes affecting the evolution of a wintertime cold air pool in the Columbia Basin. Mon. Wea. Rev., 129, 2600-2613, https://doi.org/10.1175/1520-0493(2001) 129<2600:MPATEO >2.0.CO;2.

_- X. Bian, and C. D. Whiteman, 2003: Time scale for cold-air pool breakup by turbulent erosion. Zeitshrift, 12, 229-233, https://doi.org/10.1127/0941-2948/2003/0012-0231. 